\title{
Gas hydrate and free gas estimation from seismic analysis offshore Chiloé island (Chile)
}

\author{
*Iván de la Cruz Vargas-Cordero' ${ }^{1}$ Umberta Tinivella² ${ }^{2}$ Lucía Villar-Muñoz $^{3}$, \\ Michela Giustiniani²
}

\author{
${ }^{1}$ Universidad Andrés Bello, Quillota 980, Viña del Mar, Chile. \\ ivan.vargas@unab.cl \\ 2 Istituto Nazionale di Oceanografía e di Geofísica Sperimentale (OGS), Borgo Grotta 42C, Trieste, Italy. \\ utinivella@inogs.it; mgiustiniani@inogs.it \\ 3 GEOMAR, Helmholtz Centre for Ocean Research, Wischhofstr 1-3, 24148 Kiel, Germany. \\ lucia.villar@gmail.com
}

*Corresponding author: ivan.vargas@unab.cl,lacruzvargas@gmail.com

\begin{abstract}
In this study one seismic section offshore Chiloé Island was analyzed to better define the seismic character of the hydrate-bearing sediments. The velocity analysis was used to estimate the gas-phase concentration and relate it to the geological features. The velocity model allowed us to recognize two important layers that characterize hydrate- and free gas-bearing sediments above and below the BSR respectively: one located above the BSR, characterized by high velocity $(1,800-2,200 \mathrm{~m} / \mathrm{s})$ and a second one, below the BSR, characterized by low velocity $(1,600-1,700 \mathrm{~m} / \mathrm{s})$. A weak reflector at about $100 \mathrm{~m}$ below the BSR marks the base of the second layer. AVO analysis and offset stack sections confirming that the reflector interpreted as BGR is related to free gas presence in the pore space. The velocity field is affected by lateral variation, showing maximum (above the BSR) and minimum (below the BSR) values in the sector. Here, the highest gas hydrate and free gas concentrations were calculated, obtaining $9.5 \%$ and $0.5 \%$ of total volume respectively. A variable BSR depth (from 300 to $600 \mathrm{mbsf}$ ) can be justified supposing a variable geothermal gradient (from 25 to $45^{\circ} \mathrm{C} / \mathrm{km}$ ).
\end{abstract}

Keywords: AVO, BSR, BGR, Seismic analysis, Pre-stack depth migration, Free gas, Gas hydrates.

RESUMEN. Estimación de hidratos de metano y gas libre mediante análisis sísmico frente a Chiloé (Chile). Este estudio analiza una sección sísmica marina frente a Chiloé, con el objeto de definir a través de las propiedades sísmicas las características de los sedimentos que contienen hidratos de metano. Mediante el análisis de la velocidad sísmica, es estimada la concentración de la fase-gas y su relación con estructuras geológicas. El modelo de velocidad permite reconocer dos capas importantes, una sobre el BSR de alta velocidad $(1,800-2,200 \mathrm{~m} / \mathrm{s})$ asociada a hidrato y otra por debajo del BSR de baja velocidad (1,600-1,700 m/s) relacionada con la fase-gas libre. Un débil reflector, ubicado aproximadamente a $100 \mathrm{~m}$ por debajo del BSR, marca la base de la segunda capa. Un análisis de AVO y secciones apiladas por offset permiten confirmar que este corresponde al BGR y que estaría relacionado con la presencia de gas libre. La velocidad sísmica varía lateralmente, alcanzando un valor máximo (sobre el BSR) y un mínimo (bajo el BSR) en el área. Las más altas concentraciones de hidrato y gas libre son alcanzadas en esta área $(9,5 \%$ y $0,5 \%$ del volumen total respectivamente). El aumento en la profundidad del BSR (desde 300 a $600 \mathrm{mbsf}$ ) es justificado suponiendo un gradiente geotérmico variable (desde $25 \mathrm{a} 45^{\circ} \mathrm{C} / \mathrm{km}$ ). 


\section{Introduction}

Gas hydrate occurrence in the natural environment has a global significance because of the potential energy resource represented by the large amount of hydrocarbon trapped in the hydrate phase (Milkov, 2004). The methane plays a role in global climate change (Kennett et al., 2003), and its accumulations are potential hazards which may cause damage to drilling and seabed installations (Hovland and Gudmestad, 2001).

During the last decades many efforts have been made to identify and quantify gas hydrate presence. Geophysical studies along the Chilean margin through seismic reflection data analysis have given us the opportunity to recognize the Bottom Simulating Reflector (BSR) and to map its presence (Bangs et al., 1993; Brown et al., 1996; Díaz-Naveas, 1999; Morales, 2003; Vargas-Cordero et al., 2011; VillarMuñoz et al., 2014). This reflector, representing the acoustic limit between a gas hydrate layer above the BSR and free gas layer below the BSR, is extended along the Chilean margin between $33^{\circ}$ to $47^{\circ} \mathrm{S}$. In seismic sections, the BSR presence allows defining the boundary between the high seismic velocity (i.e., the gas hydrate-bearing sediments) and the low seismic velocity because of the free gas presence (e.g., Shipley et al., 1979; Hyndman and Spence 1992; Berndt et al., 2004). In literature, few studies related to the hydrate quantification along the Chilean margin are available (Rodrigo et al., 2009; VargasCordero et al., 2010). Anyway, the results of these studies have allowed estimating the gas hydrate and free gas amounts in limited areas of Valdivia, Itata and Coyhaique offshore.

Both compressional and shear wave velocities provide information about the presence of gas hydrate and free gas in marine sediments (Tinivella and Accaino, 2000; Tinivella, 2002; Bünz et al., 2004). To interpret seismic data in terms of hydrate content, it is necessary to establish a relation between hydrate saturation in sediments and their velocity. Lee et al. (1996) developed a weighted equation model, in which hydrate is considered as part of the pore fluid. However, this model is not based on physical principles and requires empirical calibration. The velocities predicted from the cementation theory proposed by Dvorkin and Nur (1996) are much higher than those normally observed in nature (Ecker et al., 1998). Helgerud et al. (1999) introduced an effective medium theory that considers the hydrate as part of the rock frame and successfully applied their approach to the P-wave velocity data from Site 995 of ODP Leg 164 in the Blake Ridge area. Lee (2002) proposed a method based on Biot-Gassmann theory to relate the elastic properties of sediments to those of the matrix and the pore fluid. Finally, Chand et al. (2004) compared various models and found modest variations in the pattern of velocity variation with hydrate saturation if the same fluid and matrix properties are assumed. Here, it was adopted the method proposed by Tinivella (2002), based on the Biot-Gerstmann-Smith equation, successfully applied to direct measurements (ODP Leg 164; Tinivella and Lodolo, 2000) giving results in agreement with the three-phase Biot theory (Tinivella, 1999; Carcione and Tinivella, 2000).

Offshore Chilean margin and offshore Antarctic Peninsula important gas hydrate reservoirs have been detected in the last years (see for example, Vargas-Cordero et al., 2010, 2011 and Loreto et al., 2011). These regions are very sensitive to climate change as pointed out by recent studies (i.e., MarínMoreno et al., 2015), confirming that it is necessary to increase our knowledge about the quantity of gas trapped in marine sediments in order to include it in the global carbon cycle. In this context, we focused our attention to the southwest part of Chiloé Island across the continental slope between $43^{\circ}$ and $44^{\circ} \mathrm{S}$ (Fig. 1). This area is characterized by subduction of Nazca Plate below the South American continental plate along the Perú-Chile trench at a rate of about $66 \mathrm{~km} \mathrm{Ma-1} \mathrm{(Angermann} \mathrm{et} \mathrm{al.,} \mathrm{1999;} \mathrm{Kendrick} \mathrm{et}$ al., 2003). Seismic line SO161-40, analyzed in this study, is located in the area where the last glaciations have modeled the Chilean southern margin (Rabbasa and Clapperton, 1990) and the tectonic evolution of the fore arc basin included an inversion from tectonic erosion to accretion (Melnick et al., 2006). These aspects are important to consider in the seismic analysis across the BSR, because tectonic processes and glaciations determine seismic velocity changes that must be distinguished from those induced by the distribution of hydrate and free gas in the sediment pore space.

The main goal of this research is to estimate the gas hydrate and free gas amounts along the seismic line SO161-40 in order to understand the potential energy source of this area, as well as the environmental influence of the gas-phase presence. 


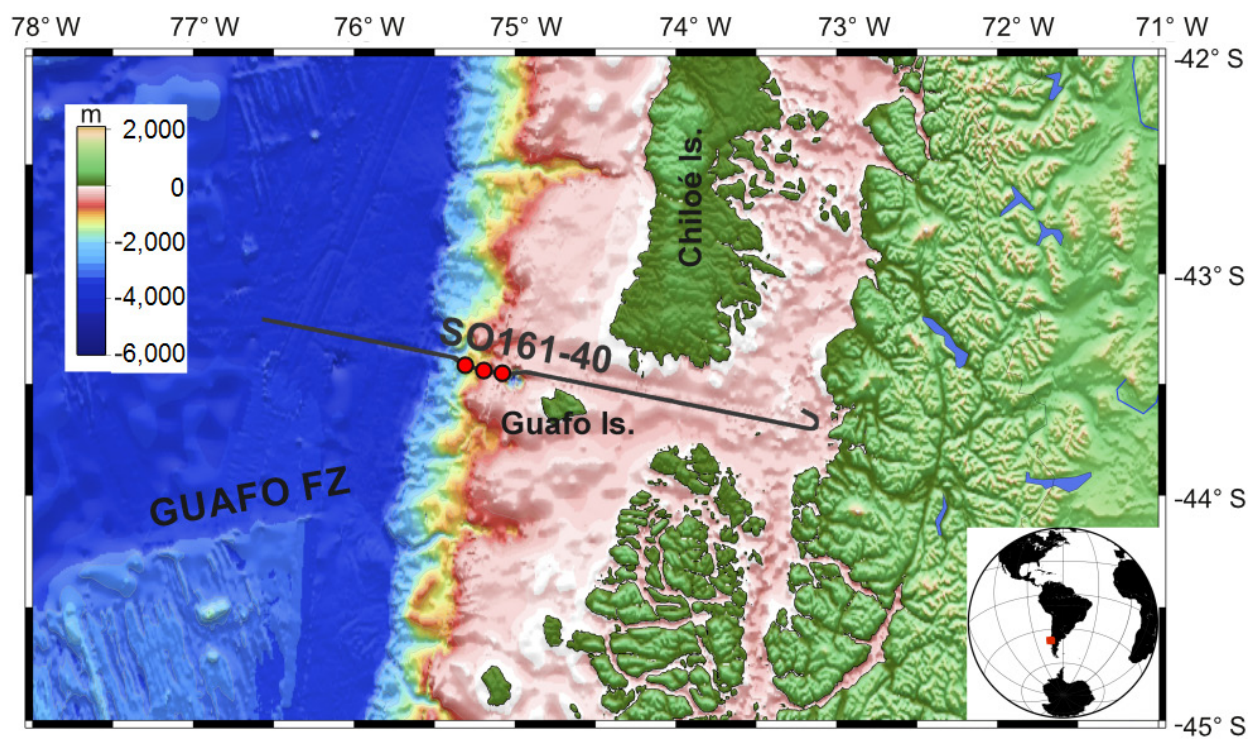

FIG. 1. Location map of the SO161-40 seismic line (solid line) and the analyzed part (red circles). Bathymetric map based on GEBCO_08 Grid (version 20091120, http://www.gebco.net (last visit 19-08-2016)).

In fact, a quantification of gas presence in the marine sediments is important not only from the energetic point of view (even if the exploitation of hydrate in marine environment is still in the early stages of development). On the other hand, it is a priority to understand if the gas released by hydrate dissociation due to pressure-temperature change can dissolve in the sea water, consume by the ecosystem or potentially reach the atmosphere increasing the green-house effect.

\section{Material and Methods}

The adopted procedure includes: a) detection of gas hydrate and free gas presence by performing an advanced seismic processing; and b) estimation of gas hydrate and free gas amounts by using velocity. Then, the geothermal gradient was estimated from sea water and BSR depths, knowing the sea bottom temperature. This procedure has been partially tested along the Chilean margin (Vargas-Cordero et al., 2010). In addition, in this study Amplitude Versus Offset (AVO) analysis was included (Yilmaz, 2001).

\subsection{Seismic data}

In this study seismic data acquired during the RV Sonne cruise SO161 (January-February 2001) in the frame of the project "Subduction Processes off Chile (SPOC)" were analyzed. The acquisition parameters of Line SO161-40 are the following: an array of 20 air guns, tuned to suppress the bubble pulse with a total volume of 54.11 a shot interval of $20 \mathrm{~s}$, producing a shot spacing of approximately $50 \mathrm{~m}$; and a streamer length of $3 \mathrm{~km}$, consisting of 132 channels. From channel 1 to 24 the inter-trace was $12.5 \mathrm{~m}$, while from channel 25 to 132 was $25 \mathrm{~m}$.

\subsection{Advanced processing and inversion modeling}

To detect and quantify the gas hydrate and free gas presence a procedure already tested was adopted (Tinivella et al., 2009; Vargas-Cordero et al., 2010). Once recognized the BSR in the post-stack section, a part $(18 \mathrm{~km})$ of the line, where the BSR was strongest and continuous, was selected to perform an advanced processing. The target includes: a) Kirchhoff Prestack time migration (PreSTM) and b) a detailed velocity model using the layer stripping approach (i.e., Yilmaz, 2001). The layers are modeled in depth with an iterative approach by using a Kirchhoff pre-stack depth migration (PreSDM) (see details in Tinivella et al., 2009).

The initial velocity is assumed constant and equal to $1,480 \mathrm{~m} / \mathrm{s}$ (water seismic velocity), assuming horizontal and vertical spacing of the grid equal to 25 and $10 \mathrm{~m}$, 
respectively. After six iterations the sea-bottom reflection within CIGs was flat suggesting that a correct migration velocity was used. Then, the velocity analysis of a second layer (top: the seafloor; bottom: a horizon between the seafloor and the BSR, hereafter called horizon 1) was performed. After 30 iterations, the velocity for the second layer was fixed. A third layer (top: horizon 1; bottom: BSR) was updated after 45 iterations. Finally, the velocity in the free gas zone below the BSR and above the so-called Base of free Gas Reflector (BGR) was updated by 20 iterations. After inserting a velocity gradient below the BGR, the final velocity model was smoothed because the PreSDM is more stable for smoothed models (Liu and Bleistein, 1995). In order to obtain an accurate image and attenuate the stretching effects, a stack of CIGs was produced considering a maximum offset of 2,500 m. Trace mixing and band-pass filter were applied to the final stacked section.

\subsubsection{BSR-derived geothermal gradient}

The geothermal gradient (dT/dZ) has been calculated with the following formula:

$$
\mathrm{dT} / \mathrm{dZ}=\left(\mathrm{T}_{\mathrm{BSR}}-\mathrm{T}_{\mathrm{SEA}}\right) /\left(\mathrm{Z}_{\mathrm{BSR}}-\mathrm{Z}_{\mathrm{SEA}}\right) \text {, }
$$

where $\mathrm{T}_{\mathrm{BSR}}$ and $\mathrm{T}_{\mathrm{SEA}}$ are the temperatures at $\mathrm{BSR}$ and at sea floor, respectively, while $\mathrm{Z}_{\mathrm{BSR}}$ and $\mathrm{Z}_{\mathrm{SEA}}$ are the depths of the BSR and the seafloor respectively (i.e., Grevemeyer et al., 2003). The BSR and the seafloor depths were obtained from the PreSDM section, while the seafloor temperature (equal to $2.2^{\circ} \mathrm{C}$ ) was taken from CTD measurements off Chile (Grevemeyer and Villinger, 2001). The estimate of the temperature at BSR is based on the dissociation temperature-pressure function of gas hydrates, considering a salinity of 35\% (Sloan, 1998; Dickens and Quinby-Hunt, 1994). This study considered that only methane is present, which is the most restrictive case (i.e., shallower BSR). In fact, even if well data pointed out the presence of $1 \%$ of ethane (Froelich et al., 1995), Vargas-Cordero et al. (2010) suggested that the effect of the ethane on theoretical BSR depth is very slight and can be neglected.

\subsection{Estimate of gas hydrate and free gas con- centrations.}

The method to estimate gas hydrate and free gas concentrations consist of comparing velocity anomalies with theoretical velocity curves in absence of gasphases. Because of the lack of direct measurements, a simplified theory, instead of more refined theory (i.e., Tinivella and Carcione, 2001; Chand et al., 2004), was used. In this case, the main error is due to the sediment property assumptions and not to the theoretical model adopted to determine the theoretical velocity versus hydrate/free gas concentration. Modified Hamilton's curves (Hamilton, 1976, 1979) were used in order to reproduce the velocity field in absence of gas or full water saturation (Tinivella, 1999).

A qualitative estimate of concentrations can be obtained by comparing the theoretical velocity for full-water saturation to the seismic velocity, evaluated by the PreSDM velocity analysis. Positive anomalies indicate the presence of gas hydrates, whereas negative anomalies indicate the presence of free gas. In order to perform a quantitative estimation, the gas-phase concentrations are increased in the theoretical formula starting from 0 . The process is stopped when the theoretical velocity fits the velocity obtained by PreSDM. The method can model two main distributions to calculate the concentrations of free gas in the pore space: a) uniform distribution (gas and water in pore space), and b) patchy distribution (all gas in patches without water). In the present study, a uniform distribution of free gas in pore space was considered, due to the low velocity observed in the free gas layer (less than 1,600 m/s; Tinivella, 2002). Missing direct measurements, the Hamilton trend for the porosity/density versus depth (Hamilton, 1979) was considered, based on a $50 \%$ porosity measured in a ODP well of the same region (Grevemeyer and Villinger, 2001).

\subsection{Amplitude versus offset curves and amplitudes change with offset}

The data processing was focused on the signalto-noise ratio increase and vertical resolution enhancement. A "preserving-amplitude" processing was adopted in order to allow a successive AVO analysis (Yilmaz, 2001). In fact, AVO analysis was performed in order to have useful information about the petro-physical properties of the shallow layers, such as the fluid content (i.e., Giustiniani et al., 2009).

The AVO effects are evident in the stacked sections obtained by using different offset ranges: lower than $500 \mathrm{~m}$ (hereafter called near-offset stacked section); from 500 to $1,700 \mathrm{~m}$ (hereafter 
called medium-offset stacked section); and higher than $1,700 \mathrm{~m}$ (hereafter called far-offset stacked section). This choice was performed evaluating the angle of incidence versus offset by using the velocity model obtained by seismic data analysis as described in the previous paragraphs. In fact, the near offset corresponds to a range of incidence angle from $0^{\circ}$ to $10^{\circ}$, the medium offset from $10^{\circ}$ to $30^{\circ}$ and the far offset means incidence angles greater than $30^{\circ}$.

\section{Results}

\subsection{PreSTM section}

The PreSTM section (Fig. 2) allows recognizing the following features:

1. Chaotic and low amplitude reflectors of the upper continental slope (from CDP 100 to 300).
2. Landward sub horizontal and discontinuous reflectors characterized by normal faults in the upper continental slope (CDP 300 to 600). Below these sediments, a high amplitude reflector with evident folding about $1 \mathrm{~s}$ from the seafloor is recognized. Note that a weak and discontinuous BSR is detectable.

3. Seaward dipping and fairly continuous reflectors, representing gently deformed sediments of the shallow upper continental slope (CDPs 600$1,400)$. The BSR is strong and continuous in this area. Below BSR a strong and continuous reflector is detectable (CDPs 800-1,200), which can be locally associated with the base of the free gas layer (BGR). Normal faults landward are recognized (CDPs 1,200-1,600). Below these faults, high amplitudes about $1 \mathrm{~s}$ from seafloor show an acoustic basement (about $3 \mathrm{~s}$ TWT).
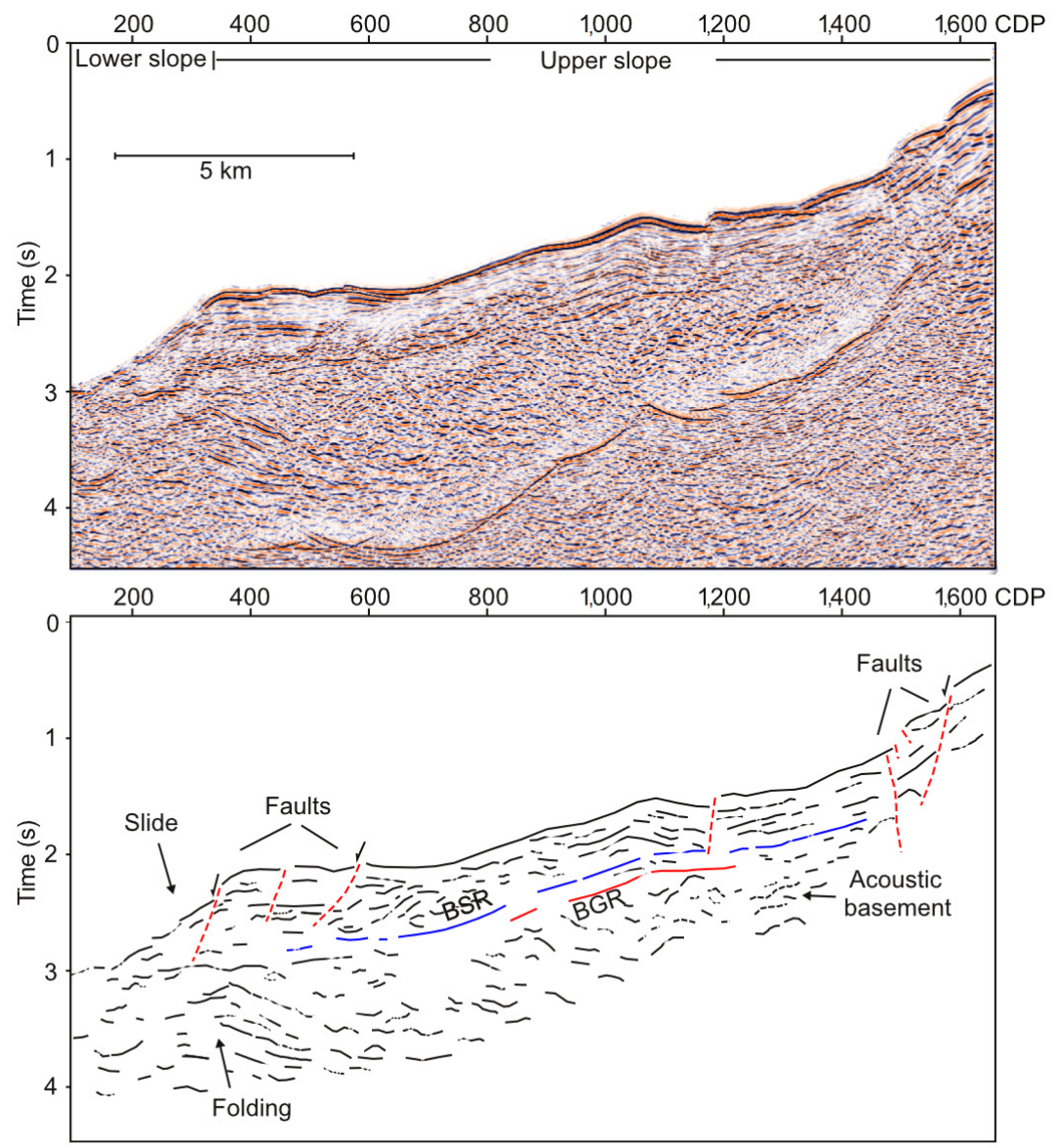

FIG. 2. Pre-stack time migrated (top) and line drawing (bottom) sections, in which the main features are indicated. 


\subsection{Velocity model and PreSDM sections}

The final velocity model shows the layer above the BSR characterized by high velocity $(1,800$ $2,200 \mathrm{~m} / \mathrm{s}$ ), with respect to the normal compacted marine sediments (Fig. 3), which can be associated to gas hydrate presence. A layer below the BSR is characterized by low velocity $(1,600-1,700 \mathrm{~m} / \mathrm{s})$ and can be associated to free gas presence (Fig. 3). A strong lateral velocity variation is evident along the section. In particular, a low velocity across the BSR is reached upward of upper continental slope (km 12-13), while a high velocity above the BSR is present downward of it ( $\mathrm{km} \mathrm{4-6).}$

The BSR is present from 4 to $16 \mathrm{~km}$. It presents a gap where the area is affected by intense deformations, characterized by faults and fractures that cut sediments going up to the seafloor. Moreover, a variable BSR depth was recognized reaching maximum value in correspondence to the boundary between the lower and upper continental slope (Fig. 3; 600 mbsf - meters below sea floor), whereas the minimum value was identified in correspondence to the uppermost part of continental slope (300 mbsf). The PreSDM section reveals possible gas hydrate and free gas thickness of about $300 \mathrm{~m}$ and $100 \mathrm{~m}$, respectively. The amplitude of the BSR is variable along the section and inversely proportional to the velocity, as expected (Fig. 3).

The BGR is present along the whole seismic section indicating the base of a layer of low velocity, which can be associated to the free gas presence. As evidenced in the blow-up in figure 3, the BGR presents a normal polarity with respect to the BSR, as expected. Note the loss of reflectivity below the BSR that could be due to the free gas presence.

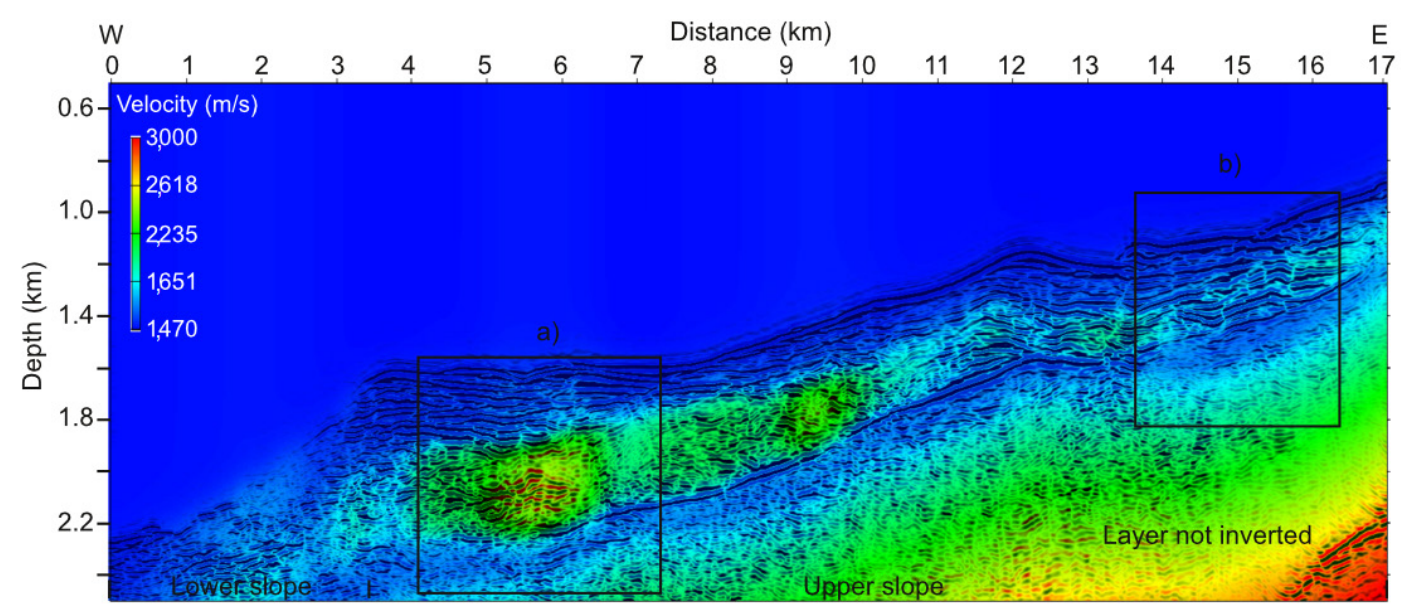

a)

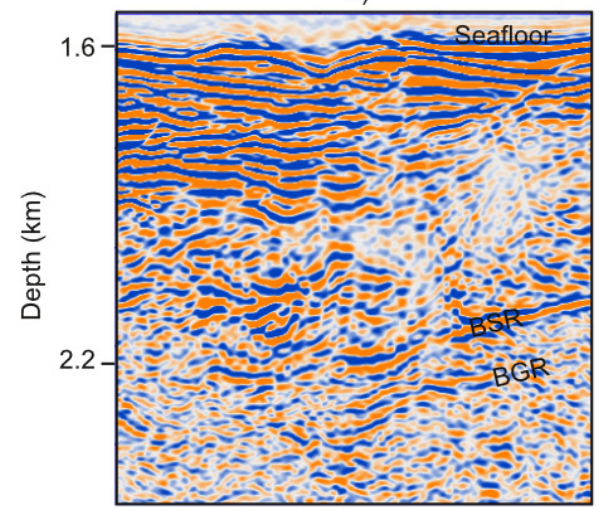

b)

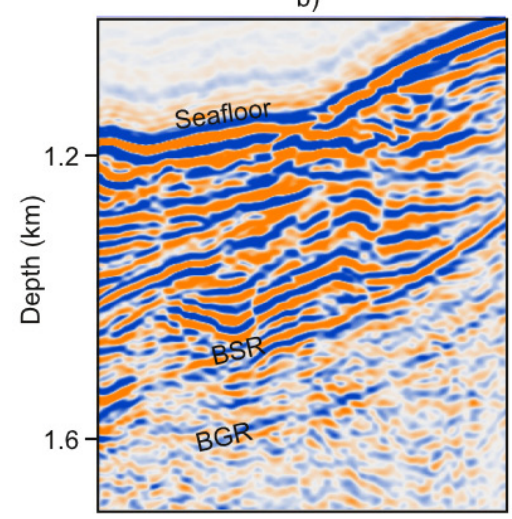

FIG. 3. Top: final velocity model superimposed to the pre-stack depth migrated section. Bottom: zoom of the selected parts, where the BSR and BGR are clearly detected. 


\subsection{BSR-derived geothermal gradient}

A variable geothermal gradient along the seismic section is recognized, with a maximum value equal to $45^{\circ} \mathrm{C} / \mathrm{km}$, located in correspondence to the uppermost part of the continental slope, and a minimum value equal to $25^{\circ} \mathrm{C} / \mathrm{km}$ westwards of it (Fig. 4). Note that the highest value is in proximity of the border line and can be affected by a higher uncertainty than the values estimated in the central part of the seismic line. The theoretical BSR depth is evaluated considering that the hydrate contains only methane, as discussed in the previous paragraphs.

\subsection{Estimate of gas hydrate and free gas concentration and AVO curves}

The results of the gas-phase estimate indicate high variability along the section. The highest gas hydrate concentration is located between 4 and $10 \mathrm{~km}$ (about $9.5 \%$ of total volume; Fig. 4), while the highest free gas concentrations ( $0.5 \%$ of total volume) are detected where highest gas hydrates concentrations are present (Fig. 4). An average of gas hydrate and free gas concentrations is obtained, $6 \%$ and $0.3 \%$, respectively. The velocity field and the related gas hydrate concentration are well characterized by the analysis described above. On the contrary, the free gas layer is difficult to analyze, because the intrinsic characteristics of the free-gas bearing sediments (i.e., the drop velocity for very small content of free gas). The AVO analysis is widely used in literature as a tool in gas-phase identification; so, in order to detect AVO effects due to gas presence, we obtained three stacked sections by using selected offset range: near, medium and far offset (Fig. 5). Then, we evaluated the theoretical PP reflection coefficient at the BGR, following the method described in Carcione and Tinivella (2000). The adopted values are reported in Table 1 and the result is shown in figure 6. As can be observed, the PP reflection coefficient is quite constant for near offset and increases slightly for medium offset. On the contrary, the PP reflection coefficient increases rapidly at far offset. The same trend is observed in the offset-stacked sections, as reported in figure 5, confirming that the reflector interpreted as BGR is effectively related to the free gas presence in the pore space. For example, this effect is evident between CDP 3,200 and 3,400, as shown in figure 5.
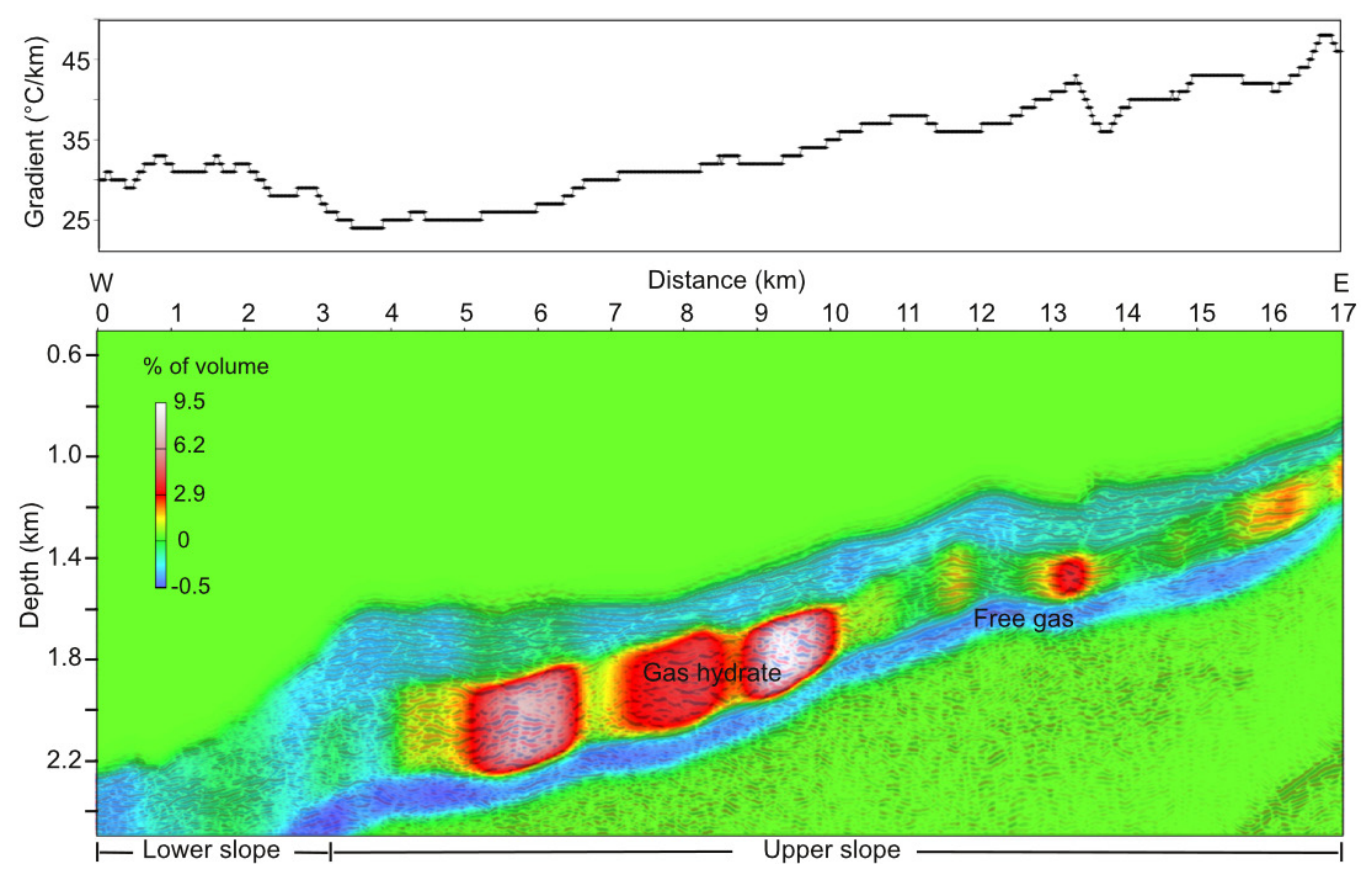

FIG. 4. Top: BSR-derived geothermal gradient. Bottom: Gas phase's concentration model superimposed to the pre-stack depth migrated section. Positive values are referred to the gas hydrate amount and negative values are referred to free gas amount. 

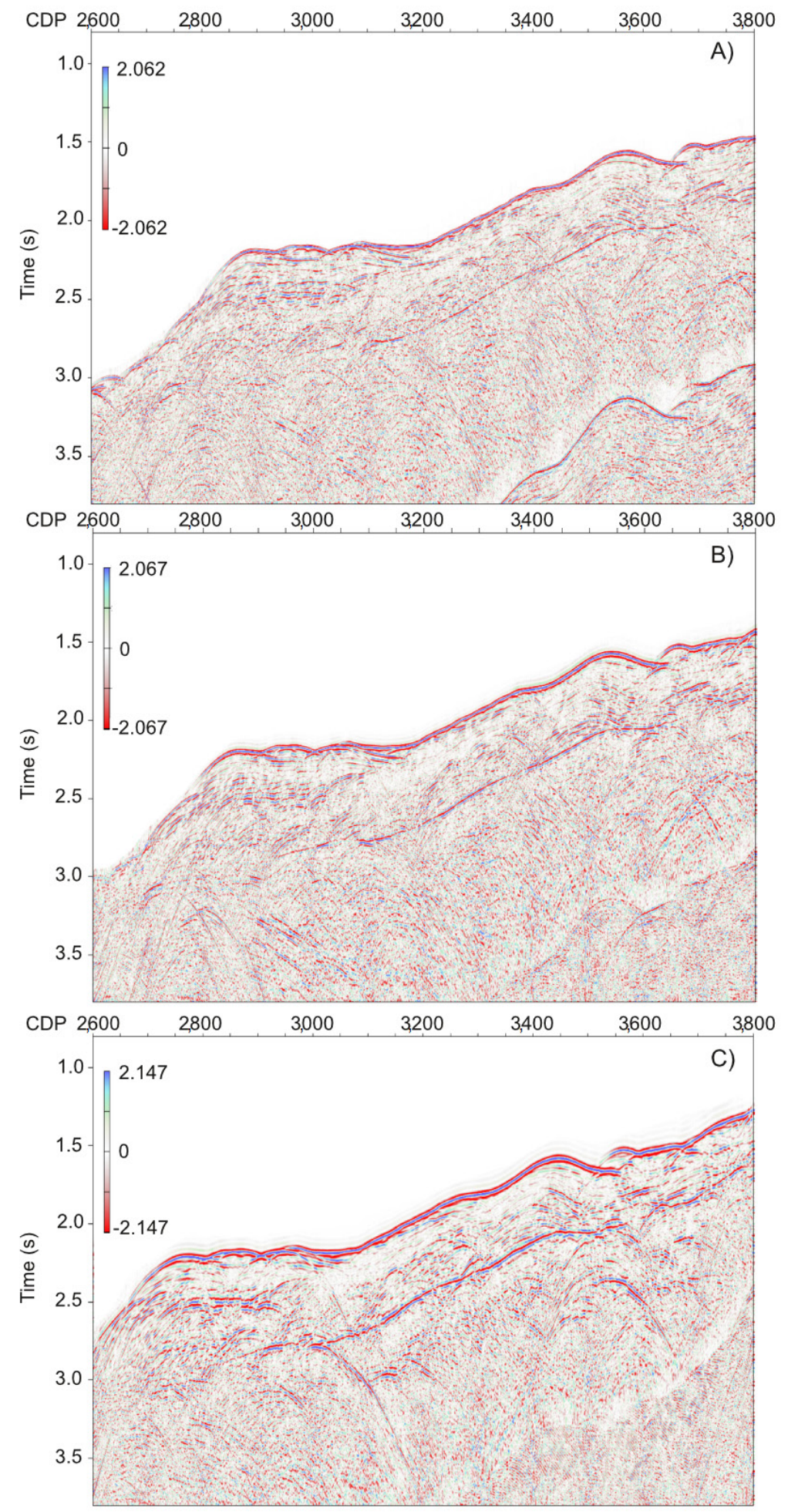

FIG. 5. Stack sections by using the traces with an offset ranging between $150 \mathrm{~m}$ and $500 \mathrm{~m}$ (panel A), between $500 \mathrm{~m}$ and $1,700 \mathrm{~m}$ (panel B) and greater than $1,700 \mathrm{~m}$ (panel C). 
TABLE 1. PETROPHISICAL PARAMETERS TO CALCULATE THEORETICAL AVO CURVE.

\begin{tabular}{lcccrr}
\hline & $\mathbf{V P}(\mathbf{m} / \mathbf{s})$ & $\mathbf{V S}(\mathbf{m} / \mathbf{s})$ & $\boldsymbol{\rho}\left(\mathbf{k g} / \mathbf{m}^{3}\right)$ & QP & QS \\
\hline Above BGR & 1,600 & 600 & 1,900 & 50 & 50 \\
Below BGR & 2,000 & 600 & 1,950 & 200 & 100 \\
\hline
\end{tabular}

VP: compressional-wave (P) velocity. VS: shear-wave (S) velocity. $\rho$ : density. QP: quality factor of P-wave velocity. QS: quality factor of S-wave velocity. BGR: base of the free gas layer. The values of velocities and densities are in agreement with the theoretical model adopted in this study. The values of QP and Qs are in agreement with Tinivella and Accaino (2000), because the lithological and tectonic characteristics in the South Shetland margin are similar to our studying area.

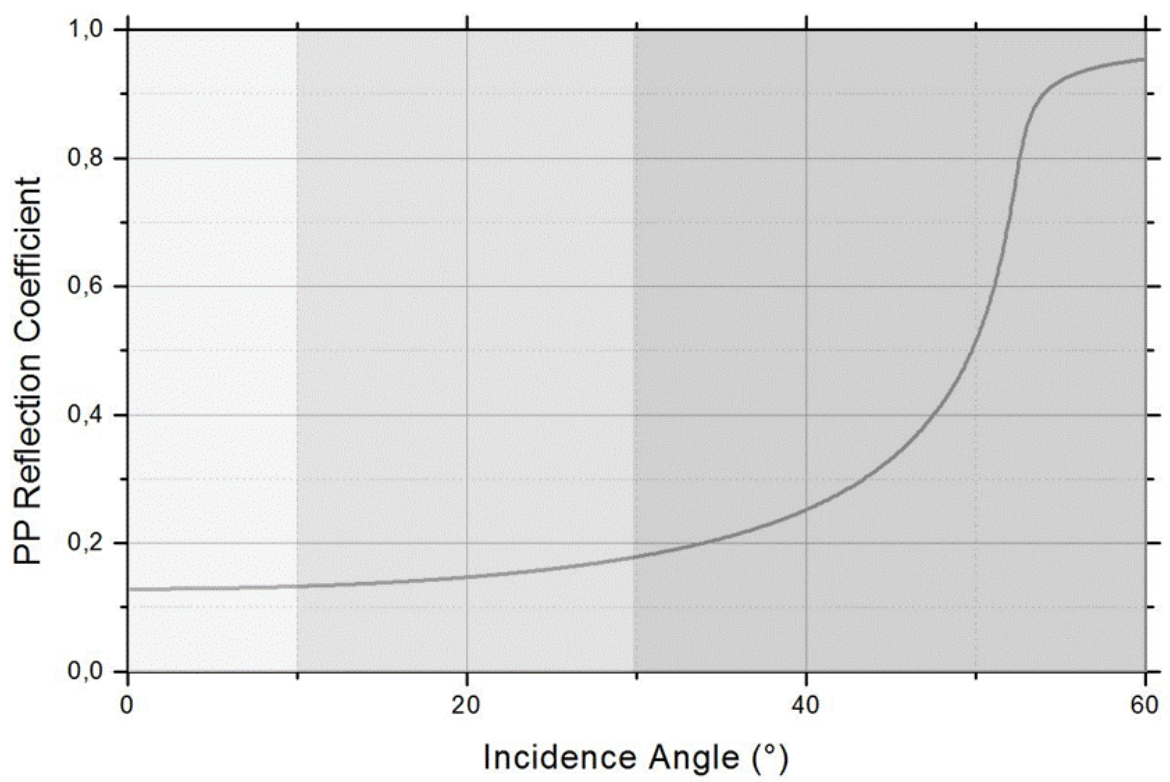

FIG. 6. Theoretical AVO curve. Dashed areas are related to offset ranging $\left(0^{\circ}-10^{\circ}\right.$ : near offset; $10^{\circ}-30^{\circ}$ : medium offset; greater than $30^{\circ}$ : far offset).

\section{Discussion and conclusions}

The seismic velocity analysis indicates strong lateral variations in the seismic section. Highest and lowest velocities are observed only where the BSR is present (Fig. 3). Note that the reflector selected below the BSR can only be locally associated to the BGR. As evidenced from seismic profiles (Figs. 2 and 3), faults and fractures show small slips affecting shallowest sediments. Moreover, small deformations within sediments reach the seafloor, thus we infer the presence of active faults. The occurrence of active faults is related mainly to lateral variation and secondly to depth variation of the BSR. Generally, along active faults intense fluids up-welling can be guided and accumulated within a trap, resulting in temperature increase of sediments. In fact, a variable BSR depth (from 300 to $600 \mathrm{mbsf}$ ) can be justified supposing a variable geothermal gradient (from 25 to about $45^{\circ} \mathrm{C} / \mathrm{km}$; Fig. 4). The estimated geothermal gradient values are in agreement with values reported in literature (Bangs et al., 1993; Brown et al., 1996; Villar-Muñoz et al., 2014). The maximum depth of the BSR, reached in the down side of upper continental slope (600 mbsf), is associated to the decrease of geothermal gradient from 45 to $25^{\circ} \mathrm{C} / \mathrm{km}$. This decrease could be justified by a combination between reduced fluid circulation and increased sedimentation rates, or with morphology effect, as can happen along the boundary between the lower and upper continental slope, which is characterized by a dip change (i.e., 
Ruppel, 1997; Ganguly et al., 2000). Clearly, the estimation of the geothermal gradient can be used for other purposes, such as regional studies including land region. The highest velocities can be related to two main factors: 1) the gas hydrate presence and 2) the change in petro-physical properties because of the different marine sediments compaction, which can be explained assuming high dewatering (Loreto et al., 2007) due to fault presence at the border of the upper slope (Fig. 2). Moreover, continental glaciations effects (Rabassa and Clapperton, 1990) may cause the porosity reduction and the consequent velocity increase as reported by Accaino et al. (2005).

Similar conclusions may be drawn analyzing the estimate of the gas-phase concentrations, derived from the velocity model. In fact, the high velocity above the BSR means high gas hydrate concentrations and the low velocity below the BSR observed in uppermost side of continental slope means high free gas concentration. It is important to underline that, in absence of direct measurements; the estimate is affected by inaccuracy: the main reliable result is the distribution of both hydrate and free gas in the pore space along the margin. Nevertheless, this estimate is consistent with the values obtained by other authors analyzing different data in the same area (Bangs et al., 1993; Froelich et al., 1995; Brown et al., 1996; Vargas-Cordero et al., 2010). For example, Brown et al. (1996) estimated that the gas hydrate concentration ranges from 5 to $20 \%$ of the pore volume, while the free gas concentration ranges from 1 to $3 \%$ of volume. In any case, this procedure can be used to determine variability at regional scale, as confirmed by the order of magnitude of our estimate. Indeed, regional and local studies (e.g., Rodrigo et al., 2009; Vargas-Cordero et al., 2009, 2010, 2011) suggest that gas hydrates are present in accretionary complexes in subduction zones, reaching $15-20 \%$ of total volume in frontal accretion, and $3-5 \%$ of total volume in basal accretion systems.

This study suggests that gas hydrate can play an important role in this part of the Chilean margin. In fact, the high local concentrations of both hydrate and free gas, as suggested by several studies, could be considered as a potential future energy resource.

\section{Acknowledgments}

The authors are very grateful to V. Damm for the seismic data provided at Federal Institute for Geosciences and Natural Resources, Germany
(BGR). This work was partially supported by the Chilean National Funds: "Fondo Nacional de Desarrollo Científico y Tecnológico (FONDECYT)". The authors largely benefited from suggestions of Dr. G. Yáñez.

\section{References}

Accaino, F.; Bohm, G.; Brancolini, G. 2005. Analysis of Antarctic glaciations by seismic reflection and refraction tomography. Marine Geology 216: 145-154.

Angermann, D.; Klotz, J.; Reiberg, C. 1999. Space-geodetic estimation of the Nazca-South American Euler vector. Earth and Planetary Science Letters 171: 329-334.

Bangs, N.L.; Sawyer, D.S.; Golovchenko, X. 1993. Free gas at the base of the gas hydrate zone in the vicinity of the Chile triple Junction. Geology 21: 905-908.

Berndt, C.; Bunz, S.; Clayton, T.; Mienert, J.; Saunders, M. 2004. Seismic character of bottom-simulatingreflectors: examples from the mid Norwegian margin. Marine and Petroleum Geology 21: 723-733.

Brown, K.M.; Bangs, N.L.; Froelich, P.N.; Kvenvolden, K.A. 1996. The nature, distribution, and origin of gas hydrate in the Chile Triple Junction region. Earth and Planetary Sciences Letters 139: 471-483.

Bünz, S.; Mienert, J. 2004. Acoustic imaging of gas hydrate and free gas at the Storegga Slide. Journal of Geophysical Research 109: 1-15.

Carcione, J.M.; Tinivella, U. 2000. Bottom simulating reflectors: Seismic velocities and AVO effects. Geophysics 65: 54-67.

Chand, S.; Minshull, T.A.; Gei, D.; Carcione, J.M. 2004. Elastic velocity models for gas hydrate bearing sediments a comparison. Geophysical Journal International 159: $573-590$.

Díaz-Naveas, J. 1999. Sediment subduction and accretion at the Chilean convergent margin between $35^{\circ}$ and $40^{\circ} \mathrm{S}$. Ph.D. Thesis (Unpublished), University of Kiel: $130 \mathrm{p}$.

Dickens, G.R.; Quinby-Hunt, M.S. 1994. Methane hydrate stability in seawater. Geophysical Research Letters 21: 2115-2118.

Dvorkin, J.; Nur, A. 1996. Elasticity of high-porosity sandstones: theory for two North Sea data sets. Geophysics 61: 1363-1370.

Ecker, C.; Dvorkin, J.; Nur, A. 1998. Sediments with gas hydrates: internal structure from seismic AVO. Geophysics 63: 1659-1669.

Froelich, P.N.; Kvenvolden, K.A.; Torres, M.E.; Waseda, A.; Didyk, B.M.; Lorenson, T.D. 1995. Geochemical 
evidence for gas hydrate in sediment near the Chile triple junction. In Proceedings of the Ocean Drilling Program, Scientific Results 141: 276-286. Texas.

Ganguly, N.; Spence, G.D.; Chapman, N.R.; Hyndman, R.D. 2000. Heat flow variations from bottom simulating reflectors on the Cascadia margin. Marine Geology 164: 53-68.

Giustiniani, M.; Accaino, F.; Picotti, S.; Tinivella, U. 2009. 3D seismic data for shallow aquifers characterisation. Journal of Applied Geophysics 68: 394-403.

Grevemeyer, I.; Díaz-Naveas, J.L.; Ranero, C.R.; Villenger, H.W. 2003. Heat Flow over the descending Nazca plate in Central Chile, $32^{\circ} \mathrm{S}$ to $41^{\circ} \mathrm{S}$ : observations from ODP Leg 202 and the occurrence of natural gas hydrates. Earth and Planetary Sciences Letters 213: 285-298.

Grevemeyer, I.; Villinger, H. 2001. Gas hydrate stability and the assessment of heat flow through continental margins. Geophysical Journal International 145: 647-660.

Hamilton, E.L. 1976. Variations of density and porosity with depth in deep-sea sediments. Journal of Sedimentary Petrology 46: 280-300.

Hamilton, E.L. 1979. Sound velocity gradients in marine sediments. Journal of the Acoustical Society of America 65: 909-922.

Helgerud, M.B.; Dvorkin, J.; Nur, A.; Sakai, A.; Collett, T.S. 1999. Elasticwave velocity in marine sediments with gas hydrates: Effective medium modelling. Geophysical Research Letters 26: 2021-2024.

Hovland, M.; Gudmestad, O.T. 2001. Potential influence of gas hydrates on seabed installations. In Natural gas hydrates: occurrence, distribution and detection (Paull, C.K.; Dillon, W.P.; editors). Geophysical Monographs American Geophysical Union 124: 307-315.

Hyndman, R.D.; Spence, G.D. 1992. A seismic study of methane hydrate marine bottom-simulating-reflectors. Journal of Geophysical Research 97: 6683-6698.

Kendrick, E.; Bevis, M.; Smalley, Jr.R.; Brooks, B.; Vargas, R.C.; Lauría, E.; Fortes, L.P.S. 2003. The Nazca-South America Euler vector and its rate of change. Journal of South American Earth Sciences 16: 125-131.

Kennett, J.P.; Cannariato, K.G.; Hendy, I.L.; Behl, R.J. 2003. Methane Hydrates in Quaternary Climate Change: The Clathrate Gun Hypothesis. American Geophysical Union: 216 p. Washington.

Lee, M.W. 2002. Biot-Gassmann theory for velocities of gas hydrate-bearing sediments. Geophysics 67 : 1711-1719.
Lee, M.W.; Hutchinson, D.R.; Collett, T.S.; Dillon, W.P. 1996. Seismic velocities for hydrate-bearing sediments using weighted equation. Journal of Geophysical Research-Solid Earth 101: 20347-20358.

Liu, Z.; Bleistein, N. 1995. Migration velocity analysis: Theory and an iterative algorithm. Geophysics 60 : 142-153.

Loreto, M.F.; Tinivella, U.; Ranero, C.R. 2007. Evidence for fluid circulation, overpressure and tectonic style along the Southern Chilean margin. Tectonophysics 429: 183-200.

Loreto, M.F.; Tinivella, U.; Accaino, F.; Giustiniani, M. 2011. Offshore Antarctic Peninsula gas hydrate reservoir characterization by geophysical data analysis. Energies 4: 39-56.

Marín-Moreno, H.; Giustiniani, M.; Tinivella, U. 2015. The Potential Response of the Hydrate Reservoir in the South Shetland Margin, Antarctic Peninsula, to Ocean Warming over the $21^{\text {st }}$ Century. Polar Research 34: 27443. doi. 10.3402/polar.v34.27443

Melnick, D.; Echtler, H.P. 2006. Inversion of forearc basins in south-central Chile caused by rapid glacial age trench fill. Geology 34: 709-712.

Milkov, A.V. 2004. Global estimates of hydrate-bound gas in marine sediments: how much is really out there? Earth Science Reviews 66: 183-197.

Morales, E. 2003. Methane hydrates in the Chilean continental margin. Electronic Journal of Biotechnology 6: 80-84.

Rabassa, J.; Clapperton, C. 1990. Quaternary glaciations of the Southern Andes, Quaternary glaciations in the Southern Hemisphere. Quaternary Science Reviews 9: 153-174.

Rodrigo, C.; González-Fernández, A.; Vera, E. 2009. Variability of the bottom-simulating reflector (BSR) and its association with tectonic structures in the Chilean margin between Arauco Gulf $\left(37^{\circ} \mathrm{S}\right)$ and Valdivia ( $\left.40^{\circ} \mathrm{S}\right)$. Marine Geophysical Researches 30: 1-19.

Ruppel, C. 1997. Anomalously cold temperatures observed at the base of the gas hydrate stability zone on the US passive margin. Geology 25: 699-702.

Shipley, T.H.; Houston, M.H.; Buffler, R.T.; Shaub, F.J.; McMillen, K.J.; Ladd, J.W.; Worzel, J.L. 1979. Seismic reflection evidence for the widespread occurrence of possible gas hydrate horizons on continental slopes and rises. American Association of Petroleum Geologists Bulletin 63: 2204-2213.

Sloan, E.D. 1998. Clathrate Hydrates of Natural Gases. Revised and expanded, CRC Press: 705 p. New York. 
Tinivella, U. 1999. A method for estimating gas hydrate and free gas concentrations in marine sediments. Bolletino Geofisica Teorica Applicata 40: 19-30.

Tinivella, U. 2002. The seismic response to overpressure versus gas 638 hydrate and free gas concentration. Journal Seismic Exploration 11: 283-305.

Tinivella, U.; Accaino, F. 2000. Compressional velocity structure and Poisson's ratio in marine sediments with gas hydrate and free gas by inversion of reflected and refracted seismic data (South Shetland Islands, Antarctica). Marine Geology 164: 13-27.

Tinivella, U.; Lodolo, E. 2000. The Blake Ridge bottom simulating reflector transect: tomographic velocity field and theoretical models to estimate hydrate quantities. In Proceedings of the Ocean Drilling Program, Scientific Results 164: 273-281.

Tinivella, U.; Carcione, J.M. 2001. Estimation of gas hydrate concentration and free gas saturation from log and seismic data. The Leading Edge 20: 200-203.

Tinivella, U.; Loreto, M.F.; Accaino, F. 2009. Regional versus detailed velocity analysis to quantify hydrate and free gas in marine sediments: The south Shetland margin target study. Geological Society of London Special Publications 319: 103-119.
Vargas-Cordero, I.; Tinivella, U.; Accaino, F.; Loreto, M.F.; Fanucci, F; Reichert, C. 2009. Analyses of bottom simulating reflections offshore Arauco and Coyhaique (Chile). Geo-Marine Letters 30: 271-281.

Vargas-Cordero, I.; Tinivella, U.; Accaino, F.; Loreto, M.F.; Fanucci, F. 2010. Thermal state and concentration of gas hydrate and free gas of Coyhaique Chilean Margin (4430' S). Marine and Petroleum Geology 27: $1148-1156$.

Vargas-Cordero, I.; Tinivella, U.; Accaino, F.; Fanucci, F.; Loreto, M.F.; Lascano, M.E.; Reichert, C. 2011. Basal and Frontal Accretion Processes versus BSR Characteristics along the Chilean Margin. Journal of Geological Research 2011: 1-10.

Villar-Muñoz, L.; Behrmann, J.H.; Díaz-Naveas, J.; Klaeschen, D.; Karstens, J. 2014. Heat flow in the southern Chile forearc controlled by largescale tectonic processes. Geo-Marine Letters 34: 185-198.

Yilmaz, O. 2001. Seismic Data Analysis: Processing, Inversion and Interpretation of Seismic Data. $2^{\text {nd }}$ Edition. Society of Exploration Geophysicists: 2027 p. Oklahoma.

Manuscript received: April 16, 2016; revised/accepted: August 8, 2016; available online: August 10, 2016. 